\title{
HARTUNG, Wolfgang, Die Spielleute im Mittelalter. Fahrende Sänger des Mittelalters. Gaukler, Dichter, Musikanten
}

\section{Martine Clouzot}

\section{OpenEdition}

Journals

Édition électronique

URL : http://journals.openedition.org/ifha/836

DOI : $10.4000 /$ ifha.836

ISSN : 2198-8943

Éditeur

IFRA - Institut franco-allemand (sciences historiques et sociales)

Référence électronique

Martine Clouzot, « HARTUNG, Wolfgang, Die Spielleute im Mittelalter. Fahrende Sänger des Mittelalters. Gaukler, Dichter, Musikanten », Revue de l'IFHA [En ligne], Date de recension, mis en ligne le 01 janvier 2005, consulté le 22 septembre 2020. URL : http://journals.openedition.org/ifha/836 ; DOI : https:// doi.org/10.4000/ifha.836

Ce document a été généré automatiquement le 22 septembre 2020.

(C)IFHA 


\title{
HARTUNG, Wolfgang, Die Spielleute im Mittelalter. Fahrende Sänger des Mittelalters. Gaukler, Dichter, Musikanten
}

\author{
Martine Clouzot
}

Dans le domaine de la recherche en histoire sociale, Die Spielleute im Mittelalter offre une synthèse réussie, approfondie et détaillée sur les jongleurs et les musiciens au Moyen Âge. W.H. fait partie des rares et excellents historiens spécialistes de la question, qu'il étudie depuis les années 1980 (voir Die Spielleute. Eine Randgruppe in der Gesellschaft des Mittelalters, Wiesbaden : Steiner [Vierteljahrschrift für Sozial- und Wirtschaftsgeschichte, Beihefte, 72], 1982 et « Gesellschaftliche Randgruppen im Spätmittelalter. Phänomen und Begriff » in : Bernhard Kirchgässner, Fritz Reuter [dir.], Städtische Randgruppen und Minderheit, Sigmaringen : Thorbecke, 1986, p. 49-114), période du renouvellement historiographique sur la marginalité et la pauvreté inauguré par Jacques Le Goff («Les marginaux dans l'occident médiéval » in : Les marginaux et les exclus dans l'histoire, Cahiers de Jussieu, 5, 1979, p. 19-28), Guy-H. Allard (Aspects de la marginalité au Moyen Âge, Montréal : L'Aurore, 1975), Michel Mollat (Les pauvres au Moyen Âge. Étude sociale, Paris : Hachette, 1978), Bronislaw Geremek (Les marginaux parisiens aux XIVe et XVe siècles, Paris : Flammarion, 1976). Le présent ouvrage est divisé en 18 chapitres. Le premier (« Die Spielleute - ein Thema für Historiker ?») a pour intérêt principal de retracer l'historiographie du sujet, en le replaçant dans son contexte politique et intellectuel, depuis le XIXe s. germanique, en passant par la France du début du XXe s. avec le livre de référence d'Edmond Faral (Les jongleurs au Moyen Âge, Paris : Champion, 1910), pour terminer aux années 1990 avec les excellents travaux des historiens allemands, notamment ceux de Franz Irsigler et Arnold Lassotta (Bettler und Gaukler, Dirnen und Henker. Randgruppen und Aussenseiter in Köln 1300-1600, Köln : Greven, 1984), Bernd-Ulrich Hergemöller (B.U.H. [dir.], Randgruppen der spätmittelaterlichen Gesellschaft, Warendorf : Fahlbusch, 1990), Antonie Schreier-Hornung (Spielleute, Fahrende, Aussenseiter. Künstler der 
mittelalterlichen Welt, Göppingen : Kümmerle, 1981). La description des Spielleute, de la définition du mot à l'aspect vestimentaire et aux origines sociales des personnes, occupe les cinq chapitres suivants. Les chapitres 7 à 9 situent le personnage sous le joug de l'Église et des théologiens. Les quatre chapitres suivants analysent sa position sociale et morale face au droit civil, aux autorités temporelles et au public citadin. Les chapitres 14 et 15 étudient les Spielleute sous l'angle de la danse en les associant aux figures du diable et de Salomé. Les trois derniers chapitres, enfin, analysent l'« insertion " professionnelle des jongleurs par les différents modes de rétribution de leur savoir-faire, dans le cadre réglementé du métier et de la confrérie, ainsi qu'à travers leurs modes de vie.

2 W.H. présente une étude abondamment documentée par les sources archivistiques, la littérature (romane, germanique, anglo-saxonne), les textes théologiques et normatifs. Le livre part du postulat que les jongleurs forment un " groupe social» (ce qui est en soi à discuter), constitué le plus souvent de marginaux - les travaux d'Ernst Schubert (Fahrendes Volk im Mittelalter, Bielefeld : Verlag für Regionalgeschichte, 1995) permettent de nuancer ce tableau -, parmi lesquels quelques-uns accèdent à la reconnaissance sociale et professionnelle. $\mathrm{Au} v \mathrm{vu}$ de l'abondance des références, on attendrait que cette passionnante étude sociologique se démarque plus nettement de certains travaux, notamment ceux de Walter Salmen (Der Spielmann im Mittelalter, Innsbruck : Helbling, 1983), et par conséquent que l'historien porte un regard encore plus critique qu'il ne l'a fait vis-à-vis du discours des médiévaux sur les jongleurs. Il n'en reste pas moins que ce livre, dont on ne peut que recommander la lecture, a le grand mérite de traiter en profondeur un sujet original et trop rare dans la recherche historique française et allemande.

Martine CLOUZOT (Université de Bourgogne, Dijon) 